\title{
Translanguaging Challenges faced by Teachers and Learners in First Grade Multilingual Literacy Classrooms in Zambia
}

\author{
Friday Nyimbili, David Sani Mwanza \\ The University of Zambia, Zambia
}

\author{
*Corresponding Author: Friday Nyimbili, The University of Zambia, Zambia
}

\begin{abstract}
The aim of this study was to establish challenges teachers and pupils faced as a result of teaching and learning using the translanguaging pedagogical practices in a multilingual grade 1 class of Lundazi District. A phenomenological design was used in one class for one term on a sample of 41 pupils and 1 teacher of literacy. Classroom observations and interviews were used to collect data that was analysed thematically. The study found that the teaching of literacy using translanguaging practices in a grade 1 multilingual class was associated with challenges like the mismatch between the language of instruction and dominant learner's familiar languages that existed in the classroom: rigidity of the language policy which was based on monolingualism throughout the learner's learning process: strict monolingual based assessment which only tested skills in the regional language and: inadequate teaching and learning materials which supported monolingual language learning. The study recommended that the Ministry of General Education and stakeholders should work together and revise provisions of the language policy guidelines so that it reflects the current linguistic composition of the language zones.
\end{abstract}

Keywords: translanguaging practices, challenges, multilingualism, monolingual, Lundazi

\section{INTRODUCTION}

Literacy levels in Zambia have been persistently low. The Grade 5 National Assessment Survey and the EGRA survey, both from 2010 show poor reading and writing abilities among learners. Another study conducted by the South African Consortium for Monitoring Education Quality (SACMEQ III) of 2010 noted that among Grade 6 learners that were tested in reading, only $27.4 \%$ were able to read at a basic competency level in the Zambian schools.

A study by Muleya (2012) found that Grade three learners in the Zambian primary schools could not read. All these were indicators pointing to the fact that despite the several policy changes starting from 1924 to date, there has not been any significant improvement in literacy levels. Further, the concept of having regional languages to teach learners has been criticised by Mwanza (2020) for being faulty because the regional languages do not represent the actual languages of play and community languages available in the different Zambian communities.

The question that begged attention was: why are literacy levels still low in Zambia when government has made several attempts through language policy changes to address the problem? Banda and Mwanza (2017) argued that Zambia's bilingual language policy was the reason because it was premised on monolingual/monoglot language ideologies that Cummins (2009) describes as a policy where learners receive instruction in one language until when they were thought to have mastered the target language in order to receive instruction in the second language. In its practical manifestation, the Zambian language of initial literacy policy is what Garcia (2009) calls two solitudes. In fact, findings from Tambulukani (2014), Mwanza (2012) and Zimba (2011) have provided sufficient evidence that using monolingual practices in the Zambian multilingual classrooms was a contributing factor to the low literacy levels in Zambia and what the policy recommended did not match with the language practices of the local people. In this view, Banda and Mwanza (2017) proposed translanguaging as a solution to epistemic access among grade one learners in a Zambia's multilingual-multi-ethnic classrooms. In other words, instead of the monolingual classroom practices which have been practiced since missionary time to date, Banda and Mwanza (2017) proposed a shift to a multilingual practices and in this case, translanguaging as pedagogic practice. 
By definition, Baker (2011:39) defined translanguaging as 'the process of making meaning, shaping experiences, gaining understanding and knowledge through the use of two languages.' Hornberger and Link, (2012:262) is also defined as, 'the purposeful pedagogical alternation of language in spoken and written, receptive and productive modes.' Translanguaging is also defined as:

The process performed by bilinguals of accessing different linguistic features or various modes of what are described as autonomous languages, in order to maximize communicative potential, (Garcia, 2009:140).

Translanguaging enables the children to realize and maximize their potentials in the learning of one language using the skills of the already existing linguistic repertoires. Garcia (2009) add that in translanguaging, languages are no longer assigned separate territories or even separate functions, but they co-exist in the same space and they are not graded with regards to their importance in the community. To this effect, translanguaging is an important pedagogical concept in the educational practices of today. Baker (2001) pointed out four educational advantages of translanguaging. These are that:

i. It may promote a deeper and fuller understanding of the subject matter.

ii. It may help the development of the weaker language.

iii. It may facilitate home-school links and cooperation.

iv. It may help the integration of fluent speakers with early learners.

Languages and dialects work as steppingstones to the provision of a link between the language being taught and the language in which the children are thinking and can express themselves better. With such advantages at hand, Zambian studies have not revealed the challenges which translanguaging comes with to both pupils and learners in the Zambian primary schools.

Literature has been alive to the fact that teachers face a number of challenges when implementing translanguaging pedagogy. Teachers and learners have not been spared from the teaching and learning challenges in the process of using translanguaging and its practices in teaching second language. Palmer and Martınez (2013) recorded that teachers feel that they can translate all linguistic items learners hold in their culture into the second or target language which is not practical and time wasting for the limited learning time. In addition, Wortham (2006) add that this leaves teachers complaining that the teaching practice is not practical, yet they do not just understand the process and they cannot just keep time. Such complaints come from teachers who fail to accommodate learners in their lesson because in the use of translanguaging, there are no language barriers. The learners translate words for the teacher and the teacher translates for the learner hence learning is a double sword affair. However, there are some words and phrases that might be beyond the learner's translation capabilities like abstract words and traditional taboos.

A study by Garcia and Lin (2016) reported that the lack of clear multilingual policy implies that schools and teachers do not have guidelines on how to use or support multiple community languages in their classrooms. Teachers do code-switch, but they are not trained to do so appropriately for educational purposes. A lack of explicit policy also makes it difficult for teacher educators to train teachers in appropriate methods to teach in multilingual contexts. Where the opportunity for translanguaging is alive, the challenges lie in the implementation of the policy, as there is not definite guidance for the teachers to use translanguaging practices in schools. Cummins (2008) argues that a trained teacher would understand that learners are not ready to use another language apart from their own in the learning situation in class. Helot (2014) revealed that some communities were not ready to learn using another language apart from their first language.

Despite some studies reporting challenges associated with translanguaging pedagogy, there is a shortage of contextual studies to bring out the challenges which teachers and learners in different learning contexts face.

\section{Purpose OF The Study}

The aim of the study was to establish challenges teachers and pupils faced as a result of teaching and learning using the translanguaging pedagogical practices in a multilingual grade one class of Lundazi District. 


\section{Methods AND Materials}

The study was purely qualitative. One classroom was sampled comprising 41 pupils. The teacher teaching literacy to the class also participated. These participants were sampled purposively. In total, the study had 42 study participants. Data was collected through in depth interviews with the teacher. The interviews were conducted during and at the end of three months in which the teacher was teaching the multilingual grade one classroom using translanguaging. Thus, the challenges being reported in this study emanated from the real life experiences of the teacher and learners. Classroom observations were also conducted in order to see how teachers were translanguaging and the observable challenges in the classroom. Thus, the study used the interview guide and the observation guide. The researchers also took field notes especially during classroom observation. Field notes were taken as the lessons were being observable. Therefore, they represent what the researchers observed. Analytically, thematic analysis was used. Thus, the data was sorted, categorised and presented under themes.

\section{RESUltS: CHALLENGES TEACHERS AND LEARNERS FACED WHEN TRANSLANGUAGING}

There were a number of challenges teachers and pupils faced as a result of teaching and learning using the translanguaging pedagogical practices in a multilingual grade one class of Lundazi District. Data was collected through interviews with the teacher while field notes complimented what was observed regarding the challenges both the teacher and the pupils faced in the translanguaging class.

\subsection{Mismatch Between Language of Instruction and Dominant Learner's Familiar Language}

The language of instruction was a challenge which hindered the acquisition of literacy by the learners in the translanguaging class. The teacher agreed to the fact that there was a mismatch between the language of instruction and the dominant familiar language of the learners in Lundazi District. She said:

Cinyanja words which are in the learner's books are not familiar to the words which learners in this area. For example, words like kamba, kumwamba, phala, kupha, ndeo, ndiwo and nsabwe have been used in the book to give examples in texts. These words are different in meaning and writing in Tumbuka as: yoŵoya, kuchanya, bala, kukoma, mbembe, dende and nyinda in the same order. Therefore, such words make the Cinyanja text not to communicate the needed information to the learners when used in class because the languages are not similar.

The teachers also acknowledged that the use of Cinyanja in the classroom where the learners were unable to understand the regional language proved to be a challenge. Learners stopped concentrating when Cinyanja was used constantly and the language became a hindrance to learning. The teacher said:

The continuous use of Cinyanja in multilingual classes make learners be lost in the class and they stop concentrating. The teacher talks to him/herself as learners are lost in the lesson. We teach in a language and this language should match the languages of the learners not assuming.

Language mismatch between the regional language and the familiar language was a challenge which needed alternative solution.

\subsection{Rigidity of the Language Policy Premised on Monolingualism}

The other challenge was enshrined in the policy which officially approved seven languages and gave them constitutional powers to be used as language of instructions in specific regions. These regions are zoned according to the ethnic grouping and settlements. It was pointed out that government has not reviewed the linguistic boundaries since 1966 to see how communities have changed and how certain languages have grown or died in some areas. The teacher stated that:

The government as well has not softened its language policy. The misinterpretation of regional, familiar and community languages has brought about confusion within the learners and teachers. At first, it was clear that a familiar language was to be used to teach literacy. Us in 


\begin{abstract}
Lundazi were supposed to use Tumbuka being the familiar language but it later changed to regional language. With this policy at hand, I feel the government has not solved the earlier problem of literacy learning to children like the Tumbuka speakers of Lundazi District.
\end{abstract}

She added that of the language policy was not flexible enough to allow teachers to use the learner's familiar language. The Cinyanja used in the district is the Lusaka version which is different from the written one and learners do not understand it too. The teacher said:

Here, Tumbuka is the only language which is dominant. If you speak Nyanja in here people will think as if you have come from Lusaka because the language is alien. The language policy which talks about regional language does not help learners acquire literacy or even make them interact since the language barrier is concrete.

The language policy was not helping the learners in class because the learners were literate in their language as they were able to write correct sounds. The teacher marked such wrong because the policy wants learners to be literate in Cinyanja and not their languages while learning. Field note 3, 2019

The use of Cinyanja to teach literacy has contributed much to the low literacy levels and late breakthrough in this district. Teachers first struggle to teach the Cinyanja language to the class before they can teach literacy in Cinyanja. Meanwhile, other children in Katete and Chadiza have no such language barriers to literacy teaching and learning.

\title{
4.3. The Monolingual Ideology in the School and Curriculum
}

The teacher revealed that school curriculum promoted teaching using one language to all the learners as long as they are in that region. The teacher said:

We have challenges as grade one teachers to teach literacy in the multilingual classes of today. The one language instruction is not a way to teach literacy today because as teachers we are faced with learners from different linguistic background which we have to consider meeting the learner's needs. So, if the syllabus and curriculum was reviewed to meet the classes of today, we can help learners learn literacy better than ever.

As much as I want to use the learner's languages to enable them to participate in translanguaging class, learners do not open up and use their different languages because they know I do not know them. It is in learners that they are supposed to use Cinyanja in class hence they fail in most cases to speak their languages. The monolingual ideologies are more rooted into learners more than you may think.

The other challenge was that teaching of literacy was only aimed at developing the regional language and its language practices or culture. This resulted into learners failing to understand some of the words which were supposed to be of value to the lesson. The teacher said:

The problem with the current language practices which we are using to literacy is that the emphasis is on one language development which is the regional language. The learner's languages are not seen to be important even if we use them in class to help learners interact. Translanguaging should go beyond one language use and allow linguistic building of other languages to enable all learners benefit.

The available teaching practices in the syllabus and curriculum that are being promoted are all premised on one language development in schools. I feel we should not force learners to start thinking in one language and make 
them abandon their languages for the sake of education. Yes, translanguaging has its own challenges but promotes what monolingual ideologies does not promote.

The monolingual ideologies resulted into teachers marking learners by considering one language as the correct language in which answers should be given.

\subsection{Translanguaging Perceived to be Time Consuming}

The other challenge the teacher faced was regarding the management of time in the translanguaging class. In the first week of introducing the teaching practice, the teacher did not manage time very well and the observation was that learners were given more time to express themselves which was good on one hand yet turned out to be a challenge as the lessons were not concluded early enough to allow another teacher into the class. The teacher said:

I did not manage to ensure that the lessons were concluded early enough in the first days of using the translanguaging practices because the class became very live. The learners over participated because they were able to make use of their language in class which was interesting. After a week, I managed to start controlling the talk and the lessons were conducted within time.

Time was also not well managed in my class because of the process of using more than one language to make meaning. When learners gave examples, the process of translation from one language into another and into another to cater for the majority of the class was taking time. Some words the learners used on a given sound were too abstract that I failed to even explain them. But it was helpful since the learners knew what was taught on that day and how to use the sound.

The sound was a common one looking at the words which the learners made when they were given chance to do so in line with the sound at hand like: mpangwe, mpungu and mpapo among others. These words were translated from one language to another to ensure the class was in tandem with the sound being taught in class. These words were not in Cinyanja but were Senga and Tumbuka words. Field Note 4, 2019.

\subsection{Phonological and Phonemic Challenges}

The teacher also revealed that there were phonological and phonemic challenges which made the classroom languages difficult to teach with literacy in the grade one classes. The learner's familiar languages were different from the regional language of instruction. The teacher explained the following:

There are phonological differences between Cinyanja and Tumbuka. Some sounds which were not in Tumbuka were a challenge to explain and translate from Cinyanja into Tumbuka. For instance, the sound /ts/ and /dz/. Even giving examples it was challenges as the Tumbuka learners found it strange to use such sounds. The language varieties were a challenge to synchronise in class.

By asking learner to close the door, the teacher wanted to make learners use the word 'citseko' but they switched to English and said 'door' and 'cijaro'. The learners also used the Tumbuka word which was different from the targeted sound of the day. The teacher translated the word 'cijalo' into 'citseke' and asked the learners to consider the 'ts' sound. With the help of the chart, the sound was explained to the learners. Field Note 5, 2019. 
Some sounds and syllables were not even in the vocabulary of the two languages while other words meant the opposite to each other like the Cinyanja word 'tiwerenge' which meant to read and the Tumbuka 'tiwerenge' which meant we go home.

The other challenge was the wrong linguistic transfer between the learner's familiar languages and Cinyanja. The Tumbuka words which never existed in Cinyanja were also a challenge when it came to spellings in a translanguaging class. Words like 'skipato' (shoes) and 'skiawia' (groundnuts) were not found in Cinyanja. Such sounds were translated and provided talking points on the orthographical differences between the two languages so that learners did not combine the spelling systems in their writing of Cinyanja language.

The other challenge reported by the teacher was regarding the combination of the classroom languages when writing a text. This was very common with the learners who did not come to school constantly and those who joined the class late for various reasons like transfer and illnesses among others. Despite the codeswitching manifesting in the learner's written works, it was not a challenge for the translanguaging teacher as it made the teacher to realise that biliteracy was taking place in class.

\subsection{Monolingual Based Assessment}

The other challenge which was observed regarding the teaching of literacy using translanguaging practices was that assessment was administered in standard Cinyanja which was read for the learners. Since learners could not read fluently, the teachers concerned read the assessment for the children as they followed and inserted the missing answers. The teacher said:

I see learners failing to make sense of the sentence not because the learners are dull, but because the learners are being asked to express their literacy in a different language. If teachers can translate their reading to suit the language of the majority learning in class, we can see performance improving in the multilingual classes after assessment.

The emphasis on language mastery as well has been a challenge in the classroom and termly assessment. We want learners to write the second language as correct as their first language which is not possible. During assessment, I feel correctness of the sentence phrasing would be ideal. We have to look at the correctness of the presented work and the meaning it is making so that mastery can be reserved as the learners advance in the grades.

We have over-emphasised on the need for improved score as the main purpose for assessment and basing literacy development which I feel is just basic and not primary. Learners are literate in their language and when it comes to assessment, we should find better ways of tapping into their languages and the literacy they hold so that we evaluate how learning is taking place. We can easily count literacy scores, but the actual literacy knowledge is not considered which is making the multilingual learners operate in the two or more languages.

During assessment, the monolingual marking key considered marking the language that was correct according to the standard Cinyanja, yet the teaching was conducted in multilanguages. This posed a challenge to the learners as it was early for them to completely separate the words and languages correctly.

\subsection{Inadequate Teaching and Learning Materials}

The challenge of teaching and learning material was also reported. It was revealed that the schools lacked learner's books for them to practice and read the target language which was being taught in school. The teachers said:

Teaching and learning materials are in a regional language which is phonemically and phonologically different from the familiar languages of 
the learners. When such books are brought to the class, they are a second barrier since the first barrier is the spoken language of instruction. Learners only look at the books and enjoy the pictures, yet the written words do not make sense to them. Such make the learners fail to learn in class.

It was established that there were insufficient literacy books for grade one term two in the school. The schools were supplied few copies of the primary Zambian language books in 2015 after the new curriculum revision took place. The teacher said:

The school was supplied with the teaching and learning materials for this new curriculum in 2014, but these were about 20 copies for each subject and term. Since then, the books have disappeared, and we cannot show the learners the writing in the books. The learners cannot read what the books say but wait for the teacher to write. This enabled me translanguage effectively since my materials were used for learning.

The conversational charts which were in use were for the NBTL program. The new curriculum has not come with charts and posters to make learners practice language in situations. This gives room to translanguaging which uses any chart to teach learners since the pictures are applicable to the learner's environment and language.

The teaching and learning materials were all monolingual designed. They already had the words and sounds which were supposed to be used on that sound of the day. The materials like charts and the books did not help the translanguaging class to effectively translanguage.

\section{Field note 6, 2019}

Through teacher creativity, translanguaging managed to go ahead with any teaching chart despite the language in which they are written. The challenge came with the phonological differences which resulted into linguistic and semantic loss.

\subsection{Monolingual Teaching and Learning Materials}

The other challenge was that the teaching and learning material which the school had for the grade one literacy class were all designed in Cinyanja and not other languages. The materials had difficult cultural words which were difficult for a multilingual class of today. The teacher explained the following:

The teaching and learning material like books and charts were all developed in standard Cinyanja which is 'Chewa' to be precise. Some of the words which are contained in the grade one book for learners are new to me and I have to ask the indigenous Chewa people for me to understand, whet more learner? The material is not friendly.

In the teaching and learning materials which the learners use for literacy, there are difficult words like 'mukeka' 'ndekha', 'ndowa', 'ndindia', 'mkute', and 'nsabwe' among others. There are no pictures attached to such words hence I just have to ask if I can explain to the learners. Such one language sided materials are not helping us in schools.

Such materials were a challenge to a translanguaging class because the teacher was always on the move to ask the people who know the words better to explain and give better examples before class time. This created a challenge for the teacher and the learners as some words were abstract.

\subsection{Sociolinguistic Environment for Language Development}

The other challenge was the sociolinguistic environment in which the language is taught and practiced. Teaching literacy using monolingual ideologies was found to be challenges because the learners did not have language models outside the classroom. This made the classroom language of instruction be limited to the teacher and the few classroom activities which did not exist in the learner's environment. The teacher said: 
Teaching literacy to the learners whose familiar language is not the language of instruction needs constant practice of the language which does not happen to our learners here. The children speak Tumbuka and Senga in their play environment and Cinyanja is never heard. So, they fail to adapt to the classroom instruction since it is not their language of play.

\begin{abstract}
Also, even at church, market and other social gatherings, Cinyanja is not used apart from in class. This affects the learner's adaptation to the classroom language because they do not speak it or hear it anywhere unless in school. This makes the teaching of literacy very difficult because we tend to repeat the same concepts, we teach every day for them to remember the words and associate to the sounds in the classroom language. It is a drawback to say the least.
\end{abstract}

As much as literacy is about reading and writing, oral literacy would be another form of testing the literacy skills in the learners whose first language is not the language of instruction. The concentration on the writing system poses a challenge on the multilingual learners in the early grade because their languages are not limited to the language of instruction. It is right to look at literacy in form of writing but as a system we do not allow the learners to use their languages to express their literacy which is not fair.

The findings have reported the challenges which teacher and pupils faced when implementing translanguaging pedagogy. Below, we discuss the findings.

\title{
5. DISCUSSION OF FINDINGS
}

There were a number of challenges which the teacher and the learner faced in the process of teaching and learning literacy using translanguaging practices in the grade one class. The first challenge was the mismatch between language of instruction and dominant learner's familiar language. Cinyanja which was the classroom language of instruction was not mutually intelligible with the learner's familiar languages in many aspects hence the anticipated literacy acquisition period was not standard in the class. For example, Cinyanja words like kamba, kumwamba, phala, kupha, ndeo, ndiwo and nsabwe have been used in the text of the grade one book to give examples. These words are different in meaning and writing in Tumbuka as: yoŵya, kuchanya, bala, kukoma, mbembe, dende and nyinda. Therefore, it can be deduced that a teacher teaching literacy in a multilingual class of Lundazi has to be familiar with the two languages if the learners are to benefit from the lessons. School communities like the ones in Lundazi have challenges regarding literacy learning due to the linguistic difference and this results into obstacles in literacy acquisition in the lower grades. In supporting the findings, Helot (2014) revealed that some communities were not ready to learn using another language apart from their first language. Indeed, Lundazi can be a better example from this study due to lexical and semantic differences between the community and regional language used for instruction. To this, Cummins (2012) argues that a trained teacher would understand that learners are not ready to use another language apart from their own in the learning situation in class. This challenge provides fertile grounds for translanguaging in the Zambian communities since the seventy languages cannot be mutually intelligible with the regional languages and support literacy instructions in the multilingual communities. This challenge also suggests that language zoning was arbitrary and does not represent the sociolinguistic situation in all the regions. In the context of the study, Chichewa (Cinyanja) is thought to be suitable for Lundazi on the premise that it is both familiar and mutually intelligible with the dominant language. Results in this study have proved this wrong as Tumbuka and Cinyanja are not mutually intelligible.

The study also found that there was rigidity of the language policy which based on monolingualism throughout the learner's learning process. This was evident from the fact that the ultimate goal of teaching literacy according to the policy was not meant to support literacy in the learner's languages, but in the official language of instruction which was not the learner's language for the multilingual class of Lundazi district. Therefore, the monolingual policy still pulls back the teacher and classroom practices to point back to monolingual instruction which derails learning. Consistent with the findings, Garcia and Lin (2017) asserted that the lack of clear multilingual policy implies that schools and 
teachers do not have guidelines on how to use or support multiple community languages in their classrooms. The education our future policy and the national literacy framework realised the need for mother tongue instruction in multilingual communities as noted: "Children arrive on the first day of school with thousands of oral vocabulary words and facet knowledge of the sound system of their mother tongue but are unable to use and build upon these linguistic skills because they are instructed in a foreign language. Dismissing this prior knowledge and trying to teach children to read in a language they are not accustomed to hearing or speaking, makes the teaching of reading difficult, especially in under-resourced schools in developing countries (MOE, 2014:12)." By foreign language, the policy was referring to English. The thinking here is that only English is a foreign language and unfamiliar language to Zambians. Yet it is clear that even Zambian languages are foreign to some pupils whose familiar languages are significantly from the designated seven regional languages. that is why Zambian children are symbolically violated in the class while the policy assumes that all the children in a region will understand one regional language. Therefore, despite realising the need for multilingual literacy instruction in the policy, the literacy practices in the classrooms still do not support the learner's languages and does not recognise the multilingualism existing in the Zambia society. Therefore, the policy has not helped to promote literacy development in the multilingual communities like Lundazi but supports monolingual literacy instructions which results into lower academic gains in school.

Study findings further revealed that translanguaging was perceived to be time consuming in the literacy multilingual class because the knowledge delivery processes were seen to be longer. The perceived longer process was from the activities that involved learner interaction with knowledge in their local languages, teacher writing the similar sound on the board and giving the learners feedback on the sound to enable them to realise the concepts behind them. The process of learner involvement was the one which was considered to be time consuming yet that is the normal process of teaching learners. Teacher's views agreed with Arocena et al., (2015) who stated that realising the learner's language in class is time worsting since the teacher gives more time to learners to participate in the lesson which creates confusion. They believed that learner participation through their local languages was time consuming and impractical to language learning situation. It must be stated that the views of the teacher in this study as well as Arocena et al (2015) views were based on monolingual monoglot ideologies. They support the silencing of learners and see it as progress and efficiency. With these monolingual ideologies being fostered throughout, monolingualism is seen desirable compared to learner participation through translanguaging. In view of these negative language ideologies, Mwanza (2020) suggests that decolonising the curriculum and the minds of the teachers should be the first step into democratising literacy classrooms in Zambia and sub-Saharan Africa. This makes the study conclude that the scholars who see multilingualism as a challenge will always promote monolingualism and see the classroom languages as a distractor to learning in literacy classes. However, if learning has to take place in any class, it has to take the learner to interact with the knowledge in the language they understand better and this is what this study can call 'ideal learning' in Zambian multilingual classrooms.

The monolingual based assessment was another challenge the teachers and learners faced in the multilingual classroom. Despite translanguaging taking place and learners showing improved literacy skills, assessment was meant to test the Cinyanja literacy skills without considering the learner's literacy skills in their various languages which was a monolingual concept. A translanguaging class build literacy in the learner's individual languages and it is these literacies which have to be assessed on how they are being applied in classroom and beyond. However, the assessment practices in Lundazi only focused on the literacy skills in the regional language, Cinyanja which disadvantaged the multilingual class and defeated the purpose of translanguaging. The monolingual based assessment spreads across the curriculum where only learners who pass the language of instruction are considered worthy advancing the university and tertiary education which renders other languages not important in the Zambian education system. This challenge was also seen to exist by Lopez et al., (2017) when they mentioned that most current initial content assessments administered within schools assume a monoglossic perspective in that they assume all students are monolingual. With such a challenge at hand, the Zambian education system therefore considers the literate people as those who are able to operate in the regional and standard language while those with the knowledge of their local 
languages and cannot show literacy in the main languages are illiterate. This concept has led to the promotion of educational gains in the seven constitutionalised regional language while supressing other languages and their subsequent educational gains.

The other challenge was that there was inadequate teaching and learning materials which supports monolingual and bilingual acquisition. The classroom observation revealed that the teacher had one literacy book which she used to teach the learners and they depended mainly on her writing on the board. This was evidence that the government has not adequately supported the teaching of literacy in Lundazi district because it has not supplied sufficient literacy instructional materials like pupil's and teacher's books as well as charts to promote literacy development in the target language. This challenge confirms why the literacy level in the target language were low. The nonexistence of these materials affected translanguaging instruction because there was no reference for correct language construction to teach comprehension and read the structure of the target language. Consistent with the findings, Sayer (2013) indicated that at the outset of implementation, concern for lack of instructional materials in the mother tongues is certainly valid, especially since the policy seems to have been implemented in "a headlong rush" constitution. Earlier, MOE (1996) accepted that there has been shortages of teaching and learning materials in the Zambian education system especially at primary school level. In addition, Nyimbili (2017) found that there was a shortage of teaching and learning materials for effective teaching of English language using learner centred techniques. Mwanza (2020) categorically states that lack of literacy teaching and learning material is one of the causes for consistent illiteracy levels in Zambia. Hence, there is need for government to provide adequate and appropriate linguistically appropriate teaching and learning materials in Lundazi District.

Theoretically, these challenges are policy related and can only be sorted out through policy realignment. Baker (2008) also observed that the monolingual policy provides dominance, discrimination, power and control, as they are manifested in the languages the teacher uses in class. A hostile environment exists for the children whose first languages are not among the seven languages and they are not supported by the teacher's linguistic practices since the policy deters him or her from translanguaging and give the learner's an opportunity to use their languages to access educational benefits. Therefore, these challenges need policy direction to respond to the learner's needs of the classrooms of today which has evolved (Mwanza, 2020; Mwanza and Bwalya, 2019).

The other challenge the teacher and learners faced was the sociolinguistic environment for language development which was not favouring multilingual development. The school environment supported monolingual instruction because other teachers did not translanguage in their lessons because the policy did not support the practice. MOE (2014:17) states that “......since learners come from different language backgrounds, it is very important that teachers conduct oral language lessons in order to expand their learners' working vocabulary in familiar languages which are used for instruction." This policy theoretically recognises familiar languages but practically points to monolingual regionalisation of language teaching. Therefore, in practice, this policy statement does not support the learner's local languages but points back to the regional language which is the language of instruction (Cinyanja). Therefore, the social environment to allow translanguaging to take place is not supported in the monolingual policy promoted Zambian schools.

In view of these findings, Zentella (2003) noted that codeswitching was not favoured by monolingual prone teachers because they thought they were leaving their language, which is the language of instruction, and used a language considered inferior. The language and current monolingual policy support the teacher's stance of using the language of instruction for communication because this is the language in which they have been given the power to control all classroom and social activities in schools. Teachers have a negative attitude towards the unofficial languages which are in class. As a result, teachers ensure that they support the monolingual teaching practices at the expense of using the available languages as a resource to learn the target language. Moreso, the hindering of literacy development in the learner's language is a bleach to the United Nations declaration that every child has the right to her or her language and culture in schools and beyond. To the foregoing, literacy development should enable the sociolinguistic environment to become supportive to the learners and their local languages if the education system is to support multiliteracy development. 
Translanguaging Challenges faced by Teachers and Learners in First Grade Multilingual Literacy Classrooms in Zambia

\section{REFERENCES}

Arafin, M. A. (2016). Bilingualism: The Beneficial and Contradictory Findings. Asian EFL

Journal, 4(2) 48-59

Baker, C. (2001). Foundations of bilingual education (2nd ed.). Clevedon: Multilingual Matters.

Baker, C. (2011). Foundations of Bilingual Education and Bilingualism. Clevedon: Multilingual Matters.

Banda, F \& Mwanza DS. (2017). Language-in-education Policy and Linguistic Diversity in Zambia: An Alternative Explanation to Low Reading Levels among Primary School Pupils. In Banja Madalitso Khulupirika (ed). Selected Readings in Education, 109- 132. Lusaka: University of Zambia Press.

Cummins, J. (2009). Transformative multiliteracies pedagogy: School-based strategies for closing the achievement gap. Multiple Voices for Ethnically Diverse Exceptional Learners, 11, 38-56.

Cummins, J. (2008). Teaching for Transfer: Challenging the Two Solitudes Assumption

in Bilingual Education. In J. Cummins \& N. H. Hornberger (Eds.), Encyclopedia of language and education: Vol. 5. Bilingual education (2nd ed., pp. 65-75). Boston: Springer Science Business Media

García, O. (2009). Bilingual education in the 21st century: A global perspective. Malden, MA and Oxford: Basil/Blackwell.

Garcia, O. and Lin, M. Y. A. (2016). Translanguaging in Bilingual Education. Springer International Publishing. Switzerland

Hélot, C. (2014). Rethinking bilingual pedagogy in Alsace: Translingual Writers and translanguaging. In A. Blackledge \& A. Creese (eds.), Heteroglossia as Practice and Pedagogy (pp. 217-238). Dordrecht, The Netherlands: Springer Science Business Media.

Hornberger, N. H., \& Link, H. (2012). Translanguaging and transnational literacies in

multilingual classrooms: A biliteracy lens. International Journal of Bilingual Education and Bilingualism, 15, 261-278.

Hornberger, N. H. (2002). Multilingual language policies and the continua of biliteracy: An

ecological approach. Language Policy, 1, 27-51

Hornberger, N. H. (2003). Continua of biliteracy: An ecological framework for educational policy, research, and practice in multilingual settings. Clevedon, UK: Multilingual Matters.

Hult, M. F. (2016). Revisiting Orientations in Language Planning: Problem, Right, and

Resource as an Analytical Heuristic. The Bilingual Review, 33 (3), 30-49

Jaffe, A. (2007). Minority language movements. In M. Heller (Ed.), Bilingualism: A social approach (pp. 50-70).

Lukama, K. (2016). The Relationship Between Phonological Awareness and Reading Ability in Selected Primary Schools of Solwezi District. (Unpublished Masters Dissertation Submitted to The University of Zambia, Lusaka).

L'opez, L. E. (2006). Cultural diversity, multilingualism and indigenous education. In O.

Garc'1a, T. Skutnabb-Kangas, \& M. Torres-Guzm’an (Eds.), Imagining multilingual schools: Languages in education and glocalization (pp. 238-261). Clevedon, England: Multilingual Matters

Martínez, R. A. (2013). Reading the world in Spanglish: Hybrid language practices and ideological contestation in a sixth-grade English language arts classroom. Linguistics and Education, 24(3), 276-288.

Ministry of Education (1996). Educating Our Future. Lusaka: Ministry of Education.

Ministry of Education (2014). Education Curriculum Framework 2013. Lusaka: Curriculum Development Centre

Mulunda, M. (2016). Mutual Intelligibility Between Chitonga Vocabulary in Instruction Materials and Lenje to Facilitate Effective Learning Of Initial Literacy Skills: The Case Of Selected Schools of Chilumba Area of Kapiri- Mposhi District, Zambia. (Unpublished Masters Dissertation Submitted to The University of Zambia, Lusaka).

Mwanza D. S (2012). The Language of Initial Literacy in a Cosmopolitan Environment: A Case of Cinyanja in Lusaka District. (Unpublished Masters Dissertation. University of Zambia, Lusaka).

Mwanza, D. S. (2017). Implications of Teachers' Attitudes Towards un-official Languages on English Language Teaching in Multilingual Zambia. Journal of Language Studies, 1 (1): 101-124.

Mwanza DS \& Bwalya V (2019). Democratisation or Symbolic Violence? An Analysis of Teachers' Language Practices in Selected Multilingual Classrooms in Chibombo District, Zambia. In F. Banda (2019). Theoretical and Applied Aspects of African Languages and Culture: Centre for Advanced Studies of African Society (CASAS), University of the Western Cape. 
Mwanza, D.S. (2020). In search of High Literacy Levels in Zambian Primary Schools: Does Duration of Mother Tongue Instruction before Transitioning into a Second Language Matter. International Journal of Education and Research. 8 (2): 119-134.

Mwanza, D.S. (2020). Critical Reflections on the Zambian Education System and the Teaching of English in Post-Colonial Zambia. English Literature and Language Review. 6 (2) : 15-23.

Nyimbili, F. (2017). The Usage of Learner Centred Techniques in the Teaching of English Language In the Secondary Schools of Lundazi District. International Journal of Humanities Social Sciences and Education (IJHSSE), 5(3) pp. 143-149.

Ruiz, R. (1984). Orientations in language planning. NABE Journal, 8, 15-34.

Sayer, P. (2013). Translanguaging, Texmex, and Bilingual Pedagogy: Emergent Bilinguals Learning Through the Vernacular. TESOL Quarterly, 47(1), 63-88.

Simachenya, M. M. (2017). Language Practices in A Multilingual Classroom Situation: A Case of Selected Primary Schools in Livingstone Urban. (Unpublished Masters Dissertation. University of Zambia, Lusaka).

Simwinga, J. (2006). The Impact of Language Policy on the Use of Minority Languages in Zambia: with Special Reference to Tumbuka and Nkoya. (Unpublished PhD Thesis. University of Zambia, Lusaka).

Tambulukani, G. K. (2014). First Language of Initial Reading: Blessing or Curse for the Zambian Children under Primary Reading Program. (Unpublished PhD. Dissertation. The University of Zambia).

Wortham, S. (2006). Learning identity: The joint emergence of social identification and academic learning. Cambridge: Cambridge University Press

Zimba, S. (2011). The Effects of Nyanja as a Language of Initial Literacy in a Predominantly Tumbuka Speaking Area: The Case of Lumezi Area of Lundazi District. Unpublished Masters Dissertation. The University of Zambia.

\section{AUTHORS' BIOGRAPHY}

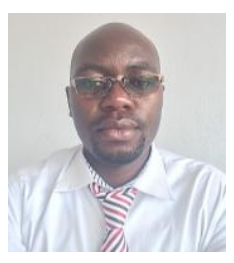

Nyimbili Friday, is a $\mathrm{Ph}$. D student at the University of Zambia, School of Education, department of Language and Social Science Education, proof reader and Part Time lecturer at Chalimbana University, Languages department.

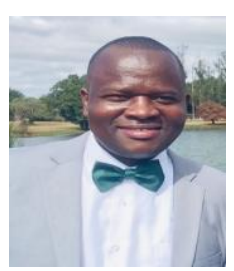

David Sani Mwanza, Senior Lecturer at the University of Zambia, School of Education and Head of department for Language and Social Science Education

Citation: Friday Nyimbili \& David Sani Mwanza. "Translanguaging Challenges faced by Teachers and Learners in First Grade Multilingual Literacy Classrooms in Zambia” International Journal on Studies in English Language and Literature (IJSELL), vol 9, no. 3, 2021, pp. 20-31. doi: https://doi.org/10.20431/23473134.0903003.

Copyright: (C) 2021 Authors. This is an open-access article distributed under the terms of the Creative Commons Attribution License, which permits unrestricted use, distribution, and reproduction in any medium, provided the original author and source are credited. 